\title{
RESEARCH ON THE AWARENESS OF PREGNANT WOMEN ABOUT DIET DURING PREGNANCY
}

\author{
Todorka Boeva, Rumyana Laleva \\ Department of Health Care, Faculty of Public Health, Medical University of Varna
}

\begin{abstract}
A good diet during pregnancy is a key to the healthy growth of the fetus. After the first trimester of the pregnancy, the body needs 300 extra calories per day, especially in the later stages when the baby grows quickly. Every woman should put on some extra weight during pregnancy. Healthy weight gain is obtained from healthy foods, which are a good source of vitamins and minerals. Correct nutrition during pregnancy protects both the health of the mother and the baby. It contributes largely to the healthy development of the pregnancy and for its successful outcome - a birth of a healthy, vital and normal-weight baby. Excessive weight gain during pregnancy is connected with complications such as diabetes, hypertension, Cesarean section, and macrosomia.
\end{abstract}

AIM: The aim of this research was to evaluate the awareness of pregnant women about diet during pregnancy.

MATERIALS AND METHODS: We used an author questionnaire with open- and closed-ended questions. The study included 46 pregnant women who visited the Antenatal Care Unit at Ambulatory Medical Center for Primary Care "St. Anthony" and Medical Center "Petinka Tsvetkova".

RESULTS AND DISCUSSION: Based on qualitative and quantitative analysis of the data obtained it was found that the majority of respondents are aware of proper nutrition during pregnancy (93\%). More than half said that they have received sufficient information $(65 \%), 11 \%$ were not informed, and those who could not decide were $24 \%$. The data showed that pregnant women prefer to receive information on the proper diet from more than one source. Sources that pregnant women are likely to use are graded as follows: the most preferred one is their obstetrician - 34\%; independent advice from a midwife - 24\%; antenatal care - $19 \%$. The Global Network (Internet) is indicated by $17 \%$ of respondents; the use of brochures as a source ranks last - $6 \%$. More than half of the respondents indicated that supplements and vitamins should be taken only in case of a deficit (52\%); those who think they have to be taken in any case are 44\%. Normal weight gain of 11-14 kg during pregnancy is indicated by $53 \%$, according to $44 \%$ of the respondents gaining weight differs from person to person.

CONCLUSIONS: The majority of pregnant women are aware of the correct diet during pregnancy. The preferred sources for obtaining information are diverse, which gives grounds to conclude that additional measures are necessary to make the midwife a source of information for pregnant women. It is encouraging that more than half of the respondents indicated normal weight gain in the range of $11-14 \mathrm{~kg}$.

Keywords: pregnant, diet, awareness

\author{
Address for correspondence: \\ Todorka Boeva \\ Medical College, Medical University of Varna \\ 84 Tsar Osvoboditel Blvd, \\ Varna \\ Phone: 0889313411; \\ e-mail:boevat@mail.bg
}

Scripta Scientifica Salutis Publicae, vol. 2, 2016, suppl. 1, pp. 23-26

Medical University of Varna 


\section{INTRODUCTION}

A good diet during pregnancy is key to the healthy development of the fetus. During pregnancy an extra 300 calories per day after the first trimester are needed, especially in the later stages of pregnancy, when the baby grows quickly (1).

Every woman should put on some extra weight during pregnancy. Healthy weight gain is obtained from healthy foods that are good sources of vitamins and minerals.

Proper nutrition during pregnancy protects both the health of the mother and the baby's health. It contributes greatly to the healthy development of the pregnancy and for its successful outcome - a birth of a healthy, vital and normal-weight baby (2).

Excessive weight gain during pregnancy is associated with complications, such as diabetes, hypertension, Cesarean section, and macrosomia.

In a study of T. Artinova the results suggest that pregnant women are active and pay attention to their diet (56\%). Seventy-two percent of respondents said they follow a diet during pregnancy and $28 \%$ adhere to rational nutrition (3).

\section{AIM}

To assess the awareness of pregnant women about diet during pregnancy.

\section{MATERIALS AND METHODS}

A questionnaire survey was performed. It consisted of an individual anonymous questionnaire form among 46 pregnant women who visited the Antenatal Care Unit at Ambulatory Medical Center for Primary Care "St. Anthony" and Medical Center "Petinka Tsvetkova". The period of study covers the months of June and July, 2016.

\section{Sociological Methods:}

$\diamond$ Questionnaire method - direct individual anonymous questionnaire with pregnant women who visited the Antenatal Care Unit. A questionnaire containing 14 questions, including 11 closed-ended and 3 open-ended.

Statistical methods for processing and analysis of information:

$\diamond$ Descriptive analysis

$\diamond$ Correlation analysis

$\diamond$ Graph analysis

\section{RESULTS AND DISCUSSION}

The study found that the majority of respondents are aware of proper nutrition during pregnancy (93\%). Only 7\% cannot assess their knowledge of proper nutrition during pregnancy (Fig. 1).

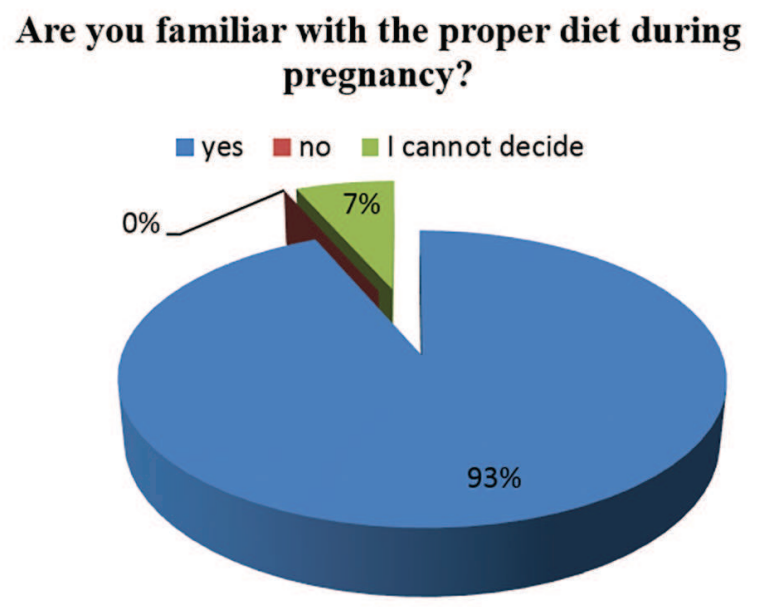

Fig. 1. Knowledge of proper nutrition during pregnancy

A similar study of T. Artinova covers the awareness of future mothers regarding the necessary diet that they must follow. The results show a good level of awareness. Fifty-six percent of the respondents said they have knowledge about proper diet during pregnancy. Partial awareness was indicated by $38 \%$ and $6 \%$ said they were not familiar with diet.

More than half of the pregnant women (65\%) said that they have received sufficient information for proper nutrition during pregnancy, $11 \%$ were not informed and those who cannot assess the available information were $24 \%$ (Fig. 2).

\section{Do you think that information received is sufficient for you?}

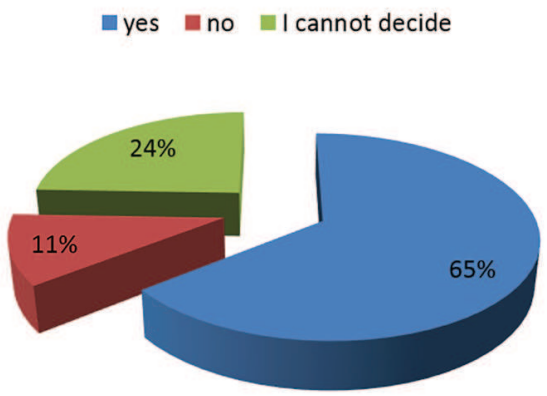

Fig. 2. Awareness about the proper diet 
Data shows that pregnant women prefer to receive information about their diet from more than one source. Sources that pregnant women would use are graded as follows: the most preferred one is their obstetrician - 34\%; a private consultation from a midwife - 24\%; Antenatal Care Unit - 19\%. The Global Network (Internet) is indicated by $17 \%$ of the respondents. Using brochures as a source ranks last - 6\% (Fig. 3).

How would you like to receive information?

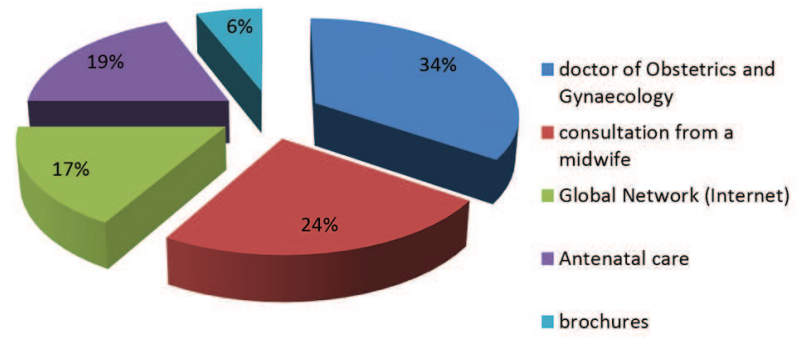

Fig. 3. Sources of information on nutrition

According to the respondents - pregnant women, food that should be taken during pregnancy is ranked as follows: first place is for fruits and vegetables; second - for dairy products, followed by cereals and sweet foods (Fig. 4).

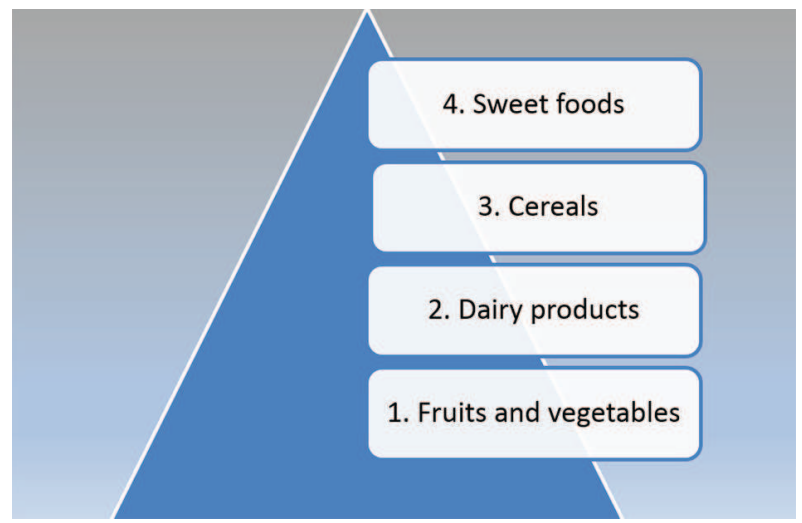

Fig. 4. Ranking of food intake during pregnancy

More than half of the respondents indicated that supplements and vitamins should be taken only in case of a deficit (52\%). Pregnant women who believe they have to be taken in any case are $44 \%$ and only $4 \%$ of respondents indicated the second half of pregnancy (Fig. 5).
Do you consider the intake of supplements and vitamins during pregnancy useful?

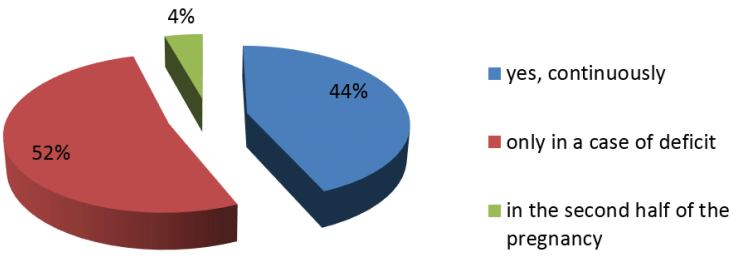

Fig. 5. Intake of supplements and vitamins during pregnancy

A positive fact is that $53 \%$ of respondents stated that a normal weight gain during pregnancy ranges from 11 to $14 \mathrm{~kg}$ and $44 \%$ are of the opinion that this differs from person to person. Those who do not know how many kilos a pregnant woman should gain are 3\% (Fig. 6).

\section{How many kilos is it normal for a woman to gain during pregnancy?}

\section{a from 11-14 kg individually I cannot decide}

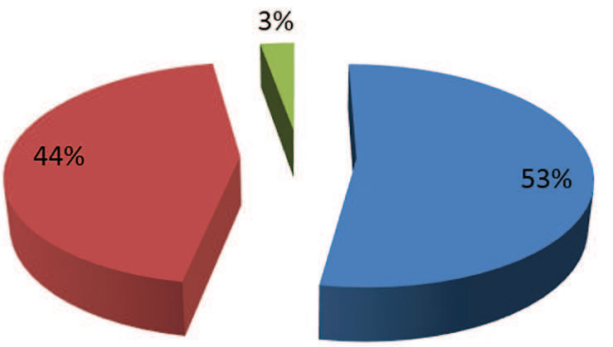

Fig. 6. Weight gain during pregnancy

\section{CONCLUSIONS}

The majority of pregnant women are aware of the correct diet during pregnancy.

The preferred sources for obtaining information are heterogeneous. This gives grounds to conclude that further measures are necessary to make the midwife a source of information for pregnant women.

More than half of the respondents are aware of the normal weight gain of 11 to $14 \mathrm{~kg}$ during pregnancy.

\section{REFERENCES}

1. www.momentofpeace.net/2008/pregnancy_diet

2. www.parentacademy.bg 
3. Artinova, T., I. Stambolova „Awareness of pregnant women for pregnancy and birth", "Health care ", issue $1,2016,5-10$.

4. www.zdrave.bg/?c=e\&id=15\&rid=155

5. Institute of Medicine. Weight gain during pregnancy: Reassessment of the instructions. Washington, DC. National Academy Press, May 2009.

6. My Pyramid for Moms (poster). United States Department of Agriculture. www.mypyramid.gov/ mypyramidmoms 